\title{
Knowledge by description
}

\section{by Russell Wahl}

IN "KNOWLEDGE BY Acquaintance and Knowledge by Description", Russell appears to distinguish two kinds of knowledge of things, knowledge by acquaintance, which is clearly the primary form, and knowledge by description, "where the object is known as "the so and so." "' While there has in recent times been some questioning of the possibility of a direct cognitive relation such as Russell's notion of acquaintance, it is clear that Russell thought we had knowledge by acquaintance, although it was restricted to certain universals, memories and the immediate data of sense, and he did not extend it to physical objects and other people. What is less clear is whether Russell held that there really was knowledge by description or whether all such knowledge should be analyzed away in terms of acquaintance. Russell's work does not give us a clear answer to this question, or rather, it answers the question in both the affirmative and negative.

Let it be clear that I am not questioning whether Russell thought that all cases of descriptive knowledge had to be explained in terms of acquaintance. I am rather questioning whether he thought there really is descriptive knowledge of things and, more importantly, whether a person can have knowledge of truths that are about things with which he is not acquainted. The issue is important since knowledge by description is central to so much of Russell's analysis of knowledge, because he held

\footnotetext{
1 "Knowledge by Acquaintance and Knowledge by Description", in Mysticism and Logic (Garden City, New York: Doubleday, Anchor Books, 1957), p. 207.
}

that most of the time when we use referring expressions they turn out to be descriptions and not names and consequently most instances of what we would call propositional knowledge turn out to involve knowledge by description.

On a first reading of "Knowledge by Acquaintance and Knowledge by Description" there do appear to be two types of knowledge of things as opposed to knowledge of truths: things are known either by acquaintance or by description. Knowledge by description is there to handle knowledge

concerning objects in cases where we know that there is one object answering a definite description, though we are not acquainted with any such object.... An object is known by description when we know that it is the 'so and so', i.e. when we know that there is one object, and no more, having a certain property; and it will generally be implied that we do not have knowledge of the same object by acquaintance. (P. 207)

Thus, for example, it would seem that I would know the next president of the United States by description if I knew that one and only one person would be the next president of the United States, and, Russell would say, I could also know truths about him, although I don't know who he is.

However, certain passages in The Problems of Philosophy indicate that Russell thought that all knowledge of things could only be by acquaintance. For example, when discussing our knowledge of a table (which is known only by description), he said "all our knowledge of the table is really knowledge of truths, and the actual thing which is the table is not, strictly speaking, known to us at all."2 And in "Knowledge by Acquaintance and Knowledge by Description" Russell argued for the plausibility of the principle of acquaintance on the grounds that "it seems scarcely possible to believe that we can make a judgment or entertain a supposition without knowing what it is that we are judging or supposing about" (p. 212). This implies that one cannot judge a proposition about something with which one is not acquainted. So knowledge is restricted to things known by acquaintance, and that an apparent case of knowledge about an object "known by description" (such as that above) becomes, on analysis, knowledge about different objects which are known by acquaintance. Such passages as this have led such authors as Sainsbury to say that Russell thought there was only one kind of knowledge of things, knowledge by acquaintance, and "merely descriptive" knowledge is a species of knowledge of truths. ${ }^{3}$

${ }^{2}$ The Problems of Philosophy (New York: Oxford University Press, 1959), p. 47. ${ }^{3}$ R. M. Sainsbury, Russell (London: Routledge and Kegan Paul, 1979), p. 30. 
Despite these passages, there is another view in Russell's writings on descriptive knowedge which makes sense of the claim that there can be knowledge of things which is not knowledge by acquaintance, and that it is correct to say that we can have knowledge of truths about things with which we are not acquainted. These two claims I take to be related, but I am more concerned with the latter. For it is a denial of this latter claim which leads one to the position that all that we can know about are the sort of things with which we can be acquainted, and that all other things are logical constructions of those things with which one is immediately acquainted. And it is a short step from here (although this is a step Russell sometimes resisted even when in this mood) to the view that all there are are those things with which we can be acquainted.

In order to motivate the less reductionist view and to see how it fits into Russell's philosophy, it is necessary to look at the origins of Russell's distinction between knowledge by acquaintance and knowledge by description, and also at the history of the theory of descriptions to which it is intimately tied.

In "Knowledge by Acquaintance and Knowledge by Description" Russell linked the whole notion of knowledge by description with his theory of denotation. This is also true in his earlier discussions of the subject. The earlier works in question are The Principles of Mathematics and some unpublished papers written on denotation during 1904 and I 905 . In one of these papers, "Points about Denoting", Russell explicitly introduced the notion of knowledge by description and related it to his theory of denoting. ${ }^{4}$ It will be instructive to look at this early theory of denotation to understand Russell's motivations for introducing the distinction in the first place, and his initial way of handling it. I think this is important because Russell often built on his earlier works even when he had changed his ideas radically, and even used terminology that did not fit well with his later views.

II

In The Principles of Mathematics, Russell thought of a proposition as a non-linguistic entity, although he occasionally used the word "proposition" to indicate something linguistic. In my presentation, I will restrict usage of "proposition" to the non-linguistic correlates of sentences, which he also held were the objects of belief, knowledge (in the case of knowledge of truths), and other propositional attitudes. For the Russell of The Principles of Mathematics, words are constituents of sentences;

4 "Points about Denoting". Unpublished manuscript in the Russell Archives, 1904/5, fol. 2. objects, relations and concepts are constitutents of propositions. A sentence is a complex of linguistic items and the corresponding proposition a complex of objects and properties (often called "concepts"). The words in the sentence mean the corresponding constituents of the proposition.

For example, if we treat "Queen Elizabeth Ir" as a logically proper name, the sentence

Queen Elizabeth $\mathbf{I}$ is under six feet tall.

expresses the proposition

Queen Elizabeth II is under six feet tall.

This proposition, which is what one is related to if one is believing, knowing, or judging that Queen Elizabeth II is under six feet tall, is composed of the actual Queen of England and the concept being under six feet tall. Very few people, if any, are acquainted with the Queen of England in the required sense, and consequently few, if any, are related to any proposition of which she is a constituent.

It is well known that Russell held that very few expressions turn out to be logically proper names, although this is more true of his later philosophy than that of The Principles of Mathematics. He held that most expressions that appear to be logically proper names are in fact disguised definite descriptions or, in his earlier terms, denoting phrases. This is a direct consequence of the principle of acquaintance: Every proposition which we can understand must be wholly composed of constituents with which we are acquainted. Such denoting phrases, on Russell's first theory of denoting, mean denoting concepts. These concepts in turn denoted the object or objects that fall under them. When I express a proposition which I am entertaining by the phrase

Queen Elizabeth II is under six feet tall

since I am not acquainted with the Queen, I am not using "Queen Elizabeth II" as a logically proper name. Thus I am actually using the name as a disguised description. My sentence should be analyzed into a more perspicuous sentence whose components mean or designate terms with which I am directly acquainted before we can discover the proposition which is the object I am related to when I believe, or know, that Queen Elizabeth II is under six feet tall. This sentence might be of the form

The present Queen of England is under six feet tall 
and, ignoring for the moment that "England" in the above is a disguised definite description, since I am not acquainted with England, this sentence will express the proposition

\section{The present Queen of England is under six feet tall}

which is the proposition I am related to when I believe that Queen Elizabeth II is under six feet tall. This proposition does not contain the Queen as a constituent, but rather the denoting concept the present Queen of England, which denotes Elizabeth II. While it is clear that Elizabeth II (the denotation) is not a constituent of this proposition, it is also clear that she is the logical subject of it. The proposition is about the Queen and not about the denoting concept which it contains as a constituent. The denoting concept denotes Elizabeth II because she and nothing else falls under the concept ... rules England now. In "On Meaning and Denotation" Russell laid out explicitly what a proposition is about: ${ }^{5}$

If a word or combination of words forming part (not the whole) of the proposition is of the kind which expresses its object, then the proposition is not about the said object; but if a word designates its object, or if a combination of words expresses an object which denotes an object, the proposition is about the object designated or denoted as the case may be [an amendment to this definition later excludes those objects designated by words which occur as a part of a denoting phrase].

While some of the details of Russell's first theory of denoting are common knowledge, what is less well known is the epistemological use he put this to. In The Principles of Mathematics Russell was very concerned about our knowledge of mathematics. Since Russell held from a very early time the principle of acquaintance, it was very important for him to allow that we could know propositions about things which are not directly constituents of them. Many mathematical propositions, Russell thought, are about infinitely many objects, not all of which we could be directly acquainted with. Russell thought these propositions, which were about these objects, did not contain them as constituents, but rather

'In this unpublished manuscript (Russell Archives, I904/5), Russell distinguished two types of meaning relations, expressing and designating, which a word would have to its meaning-relata. Proper names designated their objects, and concept words expressed their objects. Denoting phrases expressed denoting concepts which denoted certain objects. The expressing and designating relations hold between words and things, the denoting relation between concepts and things. In The Principles of Mathematics, Russell had just used the word "indicate" for both "expresses" and "designates". contained certain denoting concepts. In his 1904 papers he extended this theory to include knowledge of things other than mathematics:

It is quite certain, to begin with, that knowledge is possible with regard to an entity which can only be apprehended by means of a denoting complex. The centre of mass of the material universe (or the Solar System) at the beginning of the twentieth century is known to be some point of space, and many propositions can be ascertained concerning it; but we do not know what point it was, i.e. we know it only through denoting complexes, and not directly by an idea designating it. Thus in this case we have an entity which we can neither express nor designate, which yet is amenable to knowledge. ("On Meaning and Denotation", p. I9)

It is clear that in 1904, then, Russell thought that a sentence which contains a denoting phrase will express a proposition which contains a denoting complex as a constituent. The denotation of the concept would not be a constituent of the proposition, and yet the proposition is about the denotation. Furthermore, it is possible to have knowledge about the denotation, even though the denotation is known by description only. In "Points about Denoting" Russell used the term "knowledge by description" to characterize knowledge of an object obtained through denoting concepts:

Generally speaking, we may know, without leaving the region of general propositions, that every term of the class $a$ has the relation $R$ to one and only one term. As e.g., we know that every human being now living has one and only one father. Thus given any term of class $a$, say $x$, we know that "the term to which $x$ has the relation $R$ " has a perfectly definite denotation. Nevertheless, it is a wise child etc. This shows that to be known by description is not the same thing as to be known by acquaintance, for "the father of $x$ " is an adequate description in the sense that, as a matter of fact, there is only one person to whom it is applicable. ("Points about Denoting", p. 2)

\section{II}

We are now in a position to examine Russell's views of meaning in "Knowledge by Acquaintance and Knowledge by Description". Two changes were made in Russell's theory of propositions which are related to our inquiry. First of all, Russell no longer held that there are denoting concepts which are meant by denoting phrases and which in turn denote objects. The other change is that Russell held in I9I I that there are no such entities as propositions. He held instead that while there are facts, and situations which can be described as belief or judgment situations, 
there are no propositions which are constituents of such situations (Problems, pp. I52-3). If I am in a situation which I call believing or understanding a proposition, there is not a relation between me and a proposition, but rather a multiple relation (which is different depending on whether I am believing, knowing or understanding) between me and certain entities which Russell often called the constituents of a proposition, but which, in fact, he did not really consider to be the constituents of any proposition. Despite his use of the phrase "constituent of a proposition" in "Knowledge by Acquaintance and Knowledge by Description", he held to the view that there are no propositions in this essay (p. 212). Thus the Principle of Acquaintance (p. 2 I I) should be rephrased to read something like the following:

In order to understand a proposition (i.e. in order to be in a certain understanding state which one might express by a sentence) one must be acquainted with certain objects and properties-those which are the meanings of the parts of a sentence in a perspicuous language which results from the original sentence by analysis.

In order to know something I have to be able to understand it, so that in a belief or knowledge situation, the constituents of the situation will also be entities with which I am acquainted. This does not rule out the possibility that I can have knowledge about something with which I am not acquainted, nor does it rule out that I can be said to know a thing by description.

The second change is more important, and also has a bearing on the question of what a proposition is about. After his I905 paper "On Denoting", Russell no longer held that there were such things as denoting concepts. Instead he held that the denoting phrases have no meaning by themselves but contribute to the meaning of sentences in which they occur. ${ }^{6}$ Thus on the theory advocated in "On Denoting", the sentence "The present Queen of England is under six feet tall" means a proposition $^{7}$ of the form one and only one thing is presently ruling England and it is under six feet tall. Elizabeth II does not appear as a constituent of this

6 "On Denoting", in Essays in Analysis, ed. Douglas P. Lackey (New York: Braziller, I973), p. 105 .

At the time of his writing "On Denoting", Russell had not yet abandoned the view that sentences express propositions. In "Knowledge by Acquaintance and Knowledge by Description" he had. Consequently, this analysis would have to be modified to fit his later position. One would have to say that a person's belief or judgment should be expressed by a sentence of the form "One and only one thing is presently ruling England and it is under six feet tall", and the constituents of the judgment will correspond to the constituents of this sentence. proposition nor does a denoting concept. Nevertheless, as in the former view, a case can be made that this proposition is about Elizabeth II.

Russell did not revise his discussion of "aboutness", so the question of what a sentence is about in "Knowledge by Acquaintance and Knowledge by Description" is left open. There are two alternatives one may take with repect to "aboutness". One may hold that a sentence is about those entities meant by the words which are its constituents, or rather, are the constituents of the properly analyzed sentence, as the original may well contain incomplete symbols such as "the present Queen of England" which will be eliminated on analysis. If this is the case, one can never have a belief, judgment, or knowledge about things with which he is not acquainted, and cases of apparent knowledge by description are reduced to actual cases of knowledge by acquaintance. The other alternative is to think of the sentence as being about the objects which are either directly named by the logically proper names which occur in it, or which fall under the concepts indicated by the concept-words which are constituents of the grammatical subject of the sentence.

The first alternative ultimately makes nonsense of the distinction between knowledge by acquaintance and knowledge by description, since then it is just wrong to say that I have descriptive knowledge of Elizabeth II if I know that the present Queen of England is under six feet tall. What I do have is knowledge about certain propositional functions. There is a further difficulty with this position. If in fact the sentence "the present Queen of England is under six feet tall' is not about Elizabeth II, but rather about a construction of things people are acquainted with (or could be acquainted with), then not just the apparent names have to be analyzed, but the propositional functions as well. For I would have to reinterpret the function " $x$ rules England now", which as it stands is not the sort of function which applies to fleeting sense-data or any other possible objects of acquaintance. ${ }^{8}$

It is clear from certain passages in "Knowledge by Acquaintance and Knowledge by Description" that Russell did intend to continue the distinction between what a proposition is about and its constituents. For example, he said "We know that the man with the iron mask [who is known only by description] existed, and many propositions are known about him; but we do not know who he was" (p. 207). A little later on he says that while the actual Bismarck is "unknown to us" (and here he must mean "by acquaintance") we still know a proposition of the form " $B$ was an astute diplomatist" is true, where $B$ is a proper name ("Knowledge by

\footnotetext{
${ }^{8}$ These functions would have to be reinterpreted in the way mathematical functions are reinterpreted in Principia Mathematica.
} 
Acquaintance", p. 2 II)..$^{9}$ The discussion in this part is not much changed from that of "Points about Denoting" or "On Meaning and Denotation", where it is clear that what can be the value of the variable for the propositional functions in question does not have to be restricted to objects of acquaintance or constructions of them. This is especially important when one considers that Russell held that all physical objects, other minds, and places such as London or even the universe are known only by description.

There is a difficulty, though, with the view that merely descriptive knowledge of an object is possible. At one point Russell said: "We may now define the denotation of a phrase. If we know that the proposition ' $a$ is the so-and-so' is true, i.e. that $a$ is so-and-so and nothing else is, we call $a$ the denotation of the phrase "the so-and-so"' ("Knowledge by Acquaintance", p. 22I). This appears to make the denotation of a phrase such as "the present Queen of England" dependent on my knowledge of a proposition of the sort " $a$ rules England now and no one else does", which requires that I be acquainted with $a$. I think Russell did not want the denotation of a phrase such as this to be dependent on what I am acquainted with, and I think this is especially evident in his discussion of the denotation of "the author of Waverley", which denotes Scott because he actually wrote Waverley (p. 218). At two other points Russell indicated that a person has descriptive knowledge of an object if he knows that it is the object with certain properties (pp. 207, 223). However, given the contexts of these remarks, they cannot mean that we are required to know a proposition of the form " $a$ is so-and-so" where $a$ is a name of something with which we are acquainted, for he goes on in both cases to say that we need not be acquainted with the object in question.

I think it is a mistake to view Russell as holding in "Knowledge by Acquaintance and Knowledge by Description" the view that all knowledge is about objects of acquaintance and there really isn't merely descriptive knowledge of things. It is true that Russell later held that Piccadilly, London, etc., were logical contructions of sense-data of sensibilia, but this is not a view that is mandated by the theory of descriptions or the theory of knowledge outlined in "Knowledge by Acquaintance and Knowledge by Description"; in fact the view conflicts with these positions as they were originally set out. ${ }^{10}$

\section{Department of Philosophy}

Wabash College

${ }^{9}$ This claim is a little puzzling, for it is not clear how we could know such a proposition is

true, since on Russell's own theory we are unable to even understand it.

${ }^{10}$ I wish to thank Professors Clark, Dunn and Coffa for helpful comments. 